\title{
Percepção auditiva de fronteiras de palavras e de clíticos fonológicos no Português Brasileiro
}

DOI: http://dx.doi.org/10.21165/el.v48i2.2340

\section{Lilian Maria da Silva ${ }^{1}$}

\section{Resumo}

Este artigo analisa a percepção auditiva de fronteiras de clíticos fonológicos e de palavras prosódicas no Português Brasileiro. Para testar o quanto essas fronteiras são mais ou menos perceptíveis aos falantes nativos, desenvolvemos um experimento de percepção de fala a partir de sentenças formadas por estruturas cuja cadeia segmental correspondia, simultaneamente, à palavra prosódica e à estrutura de clítico e hospedeiro, como "encaixa" e "em caixa", respectivamente. Como resultado principal, discutimos que a percepção de fronteiras de unidades linguísticas menores, como de sílaba e de palavra, está fortemente relacionada a aspectos fonológicos da língua.

Palavras-chave: percepção de fala; palavra prosódica; estrutura de clítico e hospedeiro; Português Brasileiro.

1Universidade Estadual Paulista "Júlio de Mesquita Filho" (UNESP), São José do Rio Preto, São Paulo, Brasil; msilva.lilian@gmail.com; https://orcid.org/0000-0002-9304-5632 


\title{
Auditory perception of word and phonological clitics boundaries in Brazilian Portuguese
}

\begin{abstract}
This paper analyzes the auditory perception of boundaries of phonological clitics and prosodic words in Brazilian Portuguese. In order to test how much these boundaries are to be perceptible to the native speakers, we developed a speech perception experiment from sentences formed by structures whose segmental chain corresponded simultaneously to the prosodic word and to the clitic and host structure, like "encaixa" and "em caixa", respectively. As a main result, we argue that the perception of boundaries of minor linguistic units, such as syllable and word, is strongly related to the phonological aspects of the language.
\end{abstract}

Keywords: speech perception; prosodic word; clitic and host structure; Brazilian Portuguese.

\section{Introdução ${ }^{2}$}

Clíticos fonológicos são unidades átonas, dependentes de itens proeminentes e correspondentes a diferentes classes de palavras funcionais. Palavras monossilábicas como artigos, preposições, pronomes e conjunções são exemplos de clíticos fonológicos no Português Brasileiro (doravante, PB). Por sua vez, palavras prosódicas são definidas pela presença de acento primário e, considerando a classificação morfológica das palavras, palavras prosódicas podem corresponder a nomes, adjetivos e verbos ${ }^{3}$.

As propriedades que caracterizam clíticos fonológicos e palavras prosódicas tanto marcam diferenças entre eles quanto os relacionam. Tal relação é explicada pelas características de atonicidade e dependência dos clíticos, que precisam se ligar às palavras prosódicas para formar novas estruturas, as quais, neste artigo, serão referidas como estruturas de clítico e hospedeiro.

2 Este trabalho apresenta parte dos resultados da tese de doutorado "Grafias não convencionais de preposição e sílabas pretônicas: pistas de prosodização de clíticos preposicionais". A pesquisa contou com financiamentos da Fundação de Amparo à Pesquisa do Estado de São Paulo (FAPESP), Processos 2014/18050-7 e 2015/23238-8.

3 Câmara Jr. $(1964,1970)$ classificou os clíticos como formas dependentes, as quais se diferem, por um lado, das formas livres, já que não se sustentam sozinhas na oração, e, por outro lado, das formas presas, pois têm mais independência em relação à palavra que se liga que um afıxo a sua base. Diferentemente dos afixos, alguns clíticos são essencialmente proclíticos (i.e., préhospedeiro), como os preposicionais (por exemplo: "de maçã"), enquanto outros, como os pronominais, podem ser proclíticos (por exemplo: "se espera") e/ou enclíticos (i.e., pós-hospedeiro) (por exemplo: "espera-se"). Na classificação de Câmara Jr. (1964, 1970), palavras prosódicas equivaleriam às formas livres. 
Pesquisas que analisam a produção escrita de alunos do Ensino Fundamental observam a flutuação no registro escrito das fronteiras de palavras prosódicas e de estruturas de clítico e hospedeiro (TENANI, 2009, 2016; SILVA; TENANI, 2014; TENANI; FIEL, 2016; SILVA, 2018). Essa flutuação é marcada, em especial, em casos de segmentação não convencional de palavras (i.e. quando as fronteiras de palavra escrita são registradas fora da convenção ortográfica) como "denovo" (para "de novo") e "de vagar" (para "devagar"). Nota-se que em "denovo", cuja estrutura convencional é a de um clítico e hospedeiro, o clítico preposicional é grafado como se fosse uma sílaba interna de palavra. Na direção contrária, em "de vagar", cuja estrutura convencional é a de uma palavra prosódica, a sílaba pretônica "de" é interpretada pelo escrevente como uma preposição monossilábica que corresponde a um clítico fonológico. Com base nesses registros de segmentação em palavras, podemos afırmar que eles indiciam a complexidade no modo de organização de elementos átonos (clíticos/sílabas), a qual é marcada pela dificuldade em conceituar graficamente quando eles são elementos que constituem uma palavra (como uma de suas sílabas) e quando eles são unidades independentes que se relacionam com uma palavra.

Tendo em conta a fala, discute-se, para diferentes línguas, o domínio de prosodização de estruturas de clítico e hospedeiro na escala prosódica (SELKIRK, 1984; NESPOR; VOGEL, 1986, 2007)4. As formalizações teóricas encontradas não são consensuais e se relacionam à questão de aceitação ou negação de um domínio prosódico específico para os clíticos, o grupo clítico, proposto inicialmente por Hayes (1989) e por Nespor e Vogel (1986). Enquanto Nespor e Vogel (20077[1986]), Vogel (2009), Bisol (2000, 2005) e Veloso (2012) são favoráveis a um constituinte específico, Selkirk (1984, 1996), Vigário $(2003,2010)$ e Simioni $(2008)$ defendem a prosodização dos clíticos em domínios como a palavra prosódica e a frase fonológica. No PB, de modo convergente, Bisol $(2000,2005)$ e Simioni (2008) apresentam evidências fonológicas de que clíticos não integram o domínio da palavra prosódica, mas com ela formam um constituinte maior. Por extrapolar o propósito deste artigo, não adentraremos à problemática que envolve considerar ou não um constituinte específico de prosodização dos clíticos e às diferenças de filiação teórica entre os trabalhos referidos do PB. Assumimos, pois, a premissa de que, ao não

40 conceito de escala prosódica é originado do arcabouço da Fonologia Prosódica (SELKIRK, 1984; NESPOR; VOGEL, 1986, 2007). Essa teoria aborda a estruturação universal dos sons das línguas, a qual é derivada da interface entre sintaxe e fonologia. Dessa interface, tem origem um conjunto de estruturas, denominadas constituintes prosódicos. Segundo os fundamentos dessa teoria, o contínuo da fala é segmentado em constituintes prosódicos, que correspondem a unidades abstratas, que se evidenciam, nas línguas, por meio de fenômenos fonético-fonológicos (segmentais, rítmicos, entoacionais) que se aplicam tanto no interior quanto entre as fronteiras dos constituintes. A partir do modelo teórico de Nespor e Vogel (1986), são sete constituintes prosódicos dispostos hierarquicamente, aqui são apresentados em ordem crescente: sílaba $(\sigma)$, pé métrico $(\Sigma)$, palavra prosódica $(\omega)$, grupo clítico $(C)$, frase fonológica $(\phi)$, frase entoacional $(I)$, enunciado fonológico $(U)$. 
integrar a palavra prosódica, clítico e hospedeiro formam outro constituinte prosódico, evidenciando que essa estrutura e a palavra prosódica são duas unidades distintas no PB.

Se, por um lado, dados de fala trazem evidências da distinção entre palavras prosódicas e estruturas de clítico e hospedeiro, por outro lado, dados de escrita indiciam dificuldades na categorização e no registro gráfico de ambas como duas unidades distintas. Nesse cenário, este trabalho vai em busca de evidências com base em dados de percepção de fala. O objetivo é o de verificar se os ouvintes do PB conseguiriam, a partir do sinal acústico, identificar e categorizar o estatuto de uma sílaba átona quando ora é uma palavra funcional monossilábica (clítico) e quando ora é parte de palavra (sílaba pretônica).

Para investigar a percepção das estruturas alvo, desenvolvemos uma tarefa completion de percepção de fala (MILLOTE; WALES; CHRISTOPHE, 2007; SEVERINO, 2011; SILVA, 2018), construída a partir de palavras prosódicas e estruturas de clítico e hospedeiro que compartilham a mesma cadeia segmental (i.e. "encaixa" e "em caixa"). Antes de expor o design experimental e os procedimentos metodológicos adotados na realização do teste, apresentamos resultados de pesquisas que embasaram a escolha do tipo de tarefa de percepção realizada.

\section{Percepção de ambiguidades lexicais}

Neste trabalho, tomam-se como referências pesquisas sobre ambiguidade lexical (MILLOTE; WALES; CHRISTOPHE, 2007; SEVERINO, 2011). Essa ambiguidade diz respeito a quando estão associadas duas interpretações morfossintáticas a uma cadeia fônica que corresponde a um item lexical. Conforme adiantado e a ser mais bem detalhado na próxima seção, buscamos, com o experimento de percepção, testar a categorização de palavras prosódicas e de estruturas de clítico e hospedeiro que partilham a mesma cadeia segmental ("enfrente" e "em frente", por exemplo).

Severino (2011) e Millote, Wales e Christophe (2007) investigaram a atuação de informações fonético-fonológicas de fronteiras prosódicas na desambiguação de estruturas com mesma cadeia segmental. Dessa maneira, Severino (2011), para a variedade europeia do português, e Millote, Wales e Christophe (2007), para o francês, trataram de ambiguidades provisórias, como mostrado, respectivamente, em (01) e (02).

(01) a. A toalha larga mancha a roupa branca.

b. A toalha larga muita tinta vermelha. 
(02) a. Ce président illustre lit très peu de romans contemporains.

Esse presidente ilustre lê muito pouco de romances contemporâneos.

b. Ce président illustre la réussite sociale et professionnelle.

Esse presidente ilustra o sucesso social e profissional.

Em (01) e em (02), as palavras larga e illustre estão associadas a diferentes sentidos, os quais são identificados pela construção sintática posterior: (i) em (01a), larga é um adjetivo ligado ao substantivo toalha, enquanto em (01b), larga é forma do verbo largar; (ii) do mesmo modo no francês, em (02a), a palavra illustre funciona como adjetivo de président, porém, em (02b), é forma verbal do verbo illustre.

O fato de a palavra ambígua funcionar como adjetivo ou verbo tem consequências no fraseamento prosódico, porque envolve diferentes estruturas sintáticas. No caso de ser um adjetivo, tem-se a formação, pela relação sintática entre as palavras (o substantivo e a palavra ambígua), de uma única frase fonológica, como mostra (03). Quando a palavra alvo é um verbo, a relação sintática entre essa palavra e a palavra seguinte se altera de modo que se observa a formação de duas frases fonológicas, sendo a primeira formada pela palavra anterior à palavra alvo, no caso, um substantivo, e a segunda frase fonológica, pela palavra alvo, que funciona como forma verbal, como mostra (04).

(03) (a toalha larga)

(ce président illustre) ${ }_{\phi}$

(04) (a toalha $)_{\phi}(\text { larga })_{\phi}$

$$
\text { (ce président) }{ }_{\phi} \text { (illustre) }{ }_{\phi}
$$

Severino (2011) analisou as fronteiras de todos os constituintes prosódicos, desde a palavra prosódica até a frase entoacional, se baseando nas descrições sobre a estrutura prosódica do português europeu feitas por Frota (2000) e Vigário (2010). Para isso, a autora controlou a presença de um elemento ambíguo em distintas fronteiras prosódicas, obtendo os seguintes contrastes entre elas: 
(05) Sem fronteira prosódica versus palavra prosódica:

a. Este médico investigador irá chefiar o hospital.

b. Este médico investiga dor em doentes com leucemia.

(06) Palavra prosódica versus Grupo de Palavra Prosódica:

a. Diz-se que passa tempos muito longos a comentar as revistas.

b. Diz-se que passatempos muito longos promovem o raciocínio.

(07) Palavra prosódica versus frase fonológica:

a. Esta obra-prima terá um enorme sucesso.

b. Esta obra prima pelo bom gosto estético.

(08) Grupo de Palavra Prosódica versus frase fonológica:

a. A etiqueta indica que a placa dura suporta bastante peso.

b. A etiqueta indica que a placa dura seis meses dentro da água.

(09) Grupo de Palavra Prosódica versus frase entoacional:

a. Penso que o ciclista vencedor fará as olimpíadas em dezembro próximo.

b. Penso que o ciclista, vencedor de seis provas, ficou feliz com os resultados.

(10) Frase fonológica versus frase entoacional:

a. Uma vez chegado o professor, começarei o espetáculo.

b. Uma vez chegado o professor começou o espetáculo. 
Já Millote, Wales e Christophe (2007) investigou estruturas ambíguas somente em fronteira de frase fonológica em francês. Para caracterização dessa fronteira, os autores analisaram, por um lado, a borda direita da frase fonológica, quando a palavra antecedente e o elemento ambíguo formaram um único constituinte (cf. (ce président illustre) $)_{\phi}$ ) e, por outro lado, a borda esquerda da frase fonológica, quando a palavra ambígua constituiu um domínio sozinho (cf. (ce président) ${ }_{\phi}(\text { illustre })_{\phi}$ ). O resultado da análise acústica das duas fronteiras (direita e esquerda) mostrou que a duração da borda direita foi mais longa e o contorno de FO foi descendente, enquanto da borda esquerda a duração foi menor e o contorno foi ascendente. A conclusão dos autores foi de que, no francês, as fronteiras de frase fonológica são marcadas quando nelas estão envolvidas ambiguidades.

Millote, Wales e Christophe (2007) submeteram suas sentenças com estruturas ambíguas a uma tarefa completion de percepção, na qual foi solicitada aos participantes a elaboração de um final para um estímulo acústico ouvido (mais detalhes sobre a natureza dessa tarefa são dados na próxima seção). Na aplicação do teste com ouvintes franceses, Millote, Wales e Christophe (2007) observaram que as sentenças em que palavra ambígua correspondeu a um adjetivo, ou seja, formou uma frase fonológica com a palavra anterior, foram completadas mais corretamente quando comparadas às estruturas ambíguas que corresponderam sozinhas a uma frase fonológica. Segundo esse resultado, foi possível afirmar que evidências acústicas de fronteira prosódica atuaram sobre a percepção de estruturas sintáticas distintas. Portanto, no francês, "fronteiras de frase fonológica são espontaneamente produzidas e guiam as análises sintáticas de sentenças faladas" (MILLOTE; WALES; CHRISTOPHE, 2007, p. 905)5.

Tal como Millote, Wales e Christophe (2007), Severino (2011) adotou a mesma metodologia de tarefa completion para seu teste de percepção. No português europeu, dois tipos de informantes participaram dessa tarefa: os que conheciam os propósitos do estudo e tinham formação para identificação de fronteiras prosódicas (informante expert) e os que não conheciam o estudo e tampouco tinham conhecimento específico em prosódia (informante naïve). Os resultados revelaram que, de modo geral, os informantes se utilizaram de informações acústicas envolvidas nas fronteiras prosódicas para a desambiguação das sentenças, sobretudo, nos contrastes entre palavra prosódica versus frase fonológica, grupo de palavra prosódica versus frase entoacional, frase fonológica versus frase entoacional e, no caso específico dos informantes expert, entre grupo de palavra prosódica versus frase fonológica. Já nos contextos em que a estrutura ambígua se manteve em um domínio não ocorreu desambiguação, como nos contrastes entre sem fronteira prosódica versus palavra prosódica e palavra prosódica versus grupo de palavra prosódica.

5 Original: "Phonological phrase boundaries are thus spontaneosly produce and guide the syntatic analysis of spoken sentences". 
A partir da metodologia da tarefa completion utilizada por Millote, Wales e Christophe (2007) e Severino (2011), desenvolvemos um teste de percepção com palavra prosódica e estruturas de clítico e hospedeiro. É importante destacar que nenhuma das pesquisas de referência testaram estruturas contendo um elemento clítico. No entanto, deve ser considerado o resultado de Severino (2011), acerca de a percepção de ambiguidades no domínio da palavra ter sido baixa em relação aos domínios prosódicos que envolvem estruturas sintáticas maiores como sintagma ou sentença.

A seguir, serão apresentados os procedimentos metodológicos adotados neste estudo.

\section{Procedimentos metodológicos}

Para o teste de percepção, foram construídas 18 sentenças, distribuídas em nove pares, envolvendo palavras prosódicas e sequências de clítico e hospedeiro com a mesma cadeia segmental. Essa dinâmica de construção das sentenças pretendeu garantir que, no estímulo auditivo para o teste de percepção, estivesse presente apenas informação de natureza sonora, a fim de verificarmos se apenas essa informação seria suficiente para identificar quando a sílaba átona seria um clítico e quando ela seria uma sílaba pretônica.

Desse modo, as sentenças elaboradas envolveram ambiguidade temporária, na medida em que, embora houvesse duas estruturas morfossintáticas associadas à cadeia fônica, a informação morfossintática subsequente era suficiente para desfazer a ambiguidade, como explicitado em (11), a seguir.
a. $(0 \text { material })_{S N}(\text { encaixa })_{S V}$ nessa prateleira.
b. $(\text { O material })_{\mathrm{SN}}(\text { em caixa })_{\mathrm{SP}}$ fica separado.

Nesse exemplo, verifica-se que "nessa prateleira", em (11a), é complemento do verbo "encaixar"; já a sequência "fica separado", em (11b), possibilita a interpretação de "em caixa" como adjunto adverbial preposicionado (SP), composto pela preposição "em" seguida do substantivo "caixa".

Para desenvolvimento do experimento, a partir dos nove pares de sentenças foram construídos os estímulos auditivos, os quais compuseram uma tarefa para o ouvinte completar o enunciado, denominada na literatura por completion. Como apresentado, essa tarefa de percepção faz uso de estímulos auditivos para testar estratégias de desfazimento de ambiguidades temporárias (MILLOTE; WALES; CHRISTOPHE, 2007; SEVERINO, 2011). Assim, o procedimento dessa tarefa consiste em: 1) apresentar ao ouvinte áudio com sentenças editadas até o limite final da cadeia fônica ambígua, e 2) solicitar que o ouvinte complete, por escrito, o enunciado ouvido. O ouvinte não tem 
acesso ao enunciado final, que permitiria identificar possibilidades de interpretação da ambiguidade da cadeia fônica investigada.

Foram selecionadas, para a composição das sentenças, estruturas homófonas envolvendo as sílabas "de", "em" e "com", tendo sido construídos três pares de sentenças com cada uma das sílabas. As sentenças que deram origem aos estímulos auditivos foram gravadas por informantes de um teste de produção realizado na mesma pesquisa à qual se vincula o presente artigo (cf. SILVA, 2018). Dentre as gravações, foi selecionada a produção de uma das informantes para compor os estímulos auditivos deste experimento. A preparação dos estímulos ocorreu por meio da edição do sinal acústico, em que foi feita a eliminação de toda a cadeia fônica seguinte à estrutura alvo. Para essa tarefa, foi utilizado o software Sound Forge Pro 11.

Na aplicação do teste, foi utilizado o programa Perception Evaluation Auditive \& Visuelle (PERCEVAL), desenvolvido no Laboratório "Parole et Langage" da universidade AixMarseille, na França (ANDRÉ et al., 2017). Com o auxílio desse software, foi programada a execução de cada estímulo auditivo três vezes, a fim de garantir que os participantes do teste tivessem efetivamente compreendido os áudios. Assim, na tela do computador, os estímulos auditivos foram apresentados automaticamente e os informantes orientados a ouvir as três repetições antes de apresentar as respostas, por escrito, em uma folha numerada para cada áudio. Tão logo eles tivessem respondido a um estímulo, poderiam passar para o próximo pressionando a tecla ENTER do computador. Na realização do teste, os participantes utilizaram fones de ouvido plugados ao computador.

Para familiarizar os participantes com a dinâmica da tarefa a ser desempenhada, foram incluídas duas sentenças distratoras para treino. Quanto à forma de resposta, não foram fornecidas instruções aos informantes sobre como deveriam complementar os estímulos, de modo que tiveram total liberdade para continuar a sentença da forma como julgaram mais apropriada, sem definição de tempo para resposta. O tempo de resposta poderia ter sido quantificado, uma vez que o PERCEVAL é um programa que permitia controlar o tempo de reação para cada estímulo. Porém, essa não foi uma variável possível de ser controlada dada a natureza da tarefa solicitada, pois os complementos aos enunciados, propostos pelos participantes, variaram com frequência de tamanho (desde uma palavra até uma frase completa), fator que interferiu no tempo de resposta, mas que não pôde ser relacionado à dificuldade de compreensão do estímulo.

$\mathrm{Na}$ intenção de que não tomassem conhecimento acerca do fenômeno testado, os estímulos auditivos e os informantes foram divididos em dois grupos. Em um deles constaram os estímulos cujo alvo era a palavra prosódica e no outro grupo os estímulos agruparam as sequências de clítico e hospedeiro. Nos Quadros 1 e 2, são apresentadas as sentenças e os estímulos auditivos que compuseram cada um dos grupos. 
Quadro 1. Sentenças e estímulos auditivos para o alvo palavra prosódica

\begin{tabular}{|l|l|}
\hline \multicolumn{1}{|c|}{ Sentenças } & \multicolumn{1}{c|}{ Estímulos auditivos } \\
\hline Os militantes precisam demais da concordância do povo. & Os militantes precisam demais \\
\hline Necessitamos depressa dos documentos na reunião. & Necessitamos depressa \\
\hline O governo decreta nova reforma da previdência. & O governo decreta \\
\hline O material encaixa nessa prateleira. & O material encaixa \\
\hline Não saberemos enquanto Mariana estiver em casa. & Não saberemos enquanto \\
\hline $\begin{array}{l}\text { Esperamos que enfrente com coragem seus maiores } \\
\text { problemas. }\end{array}$ & Esperamos que enfrente \\
\hline O Bruno sofreu congestão na mesa do bar. & O Bruno sofreu congestão \\
\hline $\begin{array}{l}\text { Hoje cedo compus novos poemas, com versos de dez } \\
\text { sílabas. }\end{array}$ & Hoje cedo compus \\
\hline Discutimos contextos para pintar o novo quadro. & Discutimos contextos \\
\hline
\end{tabular}

Fonte: Elaboração própria.

Quadro 2. Sentenças e estímulos auditivos para o alvo clítico

\begin{tabular}{|l|l|}
\hline \multicolumn{1}{|c|}{ Sentenças } & \multicolumn{1}{c|}{ Estímulos auditivos } \\
\hline Os militantes precisam de mais pessoas na passeata. & Os militantes precisam de mais \\
\hline Necessitamos de pressa com os documentos firmados. & Necessitamos de pressa \\
\hline O governo de Creta discute propostas na reunião. & O governo de Creta \\
\hline O material em caixa fica separado. & O material em caixa \\
\hline Não saberemos em quanto tempo Mara estará em casa. & Não saberemos em quanto \\
\hline $\begin{array}{l}\text { Esperamos que em frente do colégio construam boas } \\
\text { calçadas. }\end{array}$ & Esperamos que em frente \\
\hline O Bruno sofreu com gestão de funcionários. & O Bruno sofreu com gestão \\
\hline Hoje cedo com pus na sua garganta, o Bruno foi ao médico. & Hoje cedo com pus \\
\hline Discutimos com textos as teorias linguísticas. & Discutimos com textos \\
\hline
\end{tabular}

Fonte: Elaboração própria. 
Os participantes do experimento de percepção foram nove graduandos do curso de Licenciatura em Letras do IBILCE/UNESP. Todos eram falantes nativos do PB e residentes na região do noroeste paulista. Os participantes não apresentavam quaisquer problemas auditivos que pudessem dificultar o entendimento dos estímulos e, além disso, aceitaram participar voluntariamente deste estudo. Somado a esse perfil geral dos participantes, vale ressaltar outro aspecto importante que diz respeito ao fato de os sujeitos estarem em formação superior em língua portuguesa, característica que garante que as respostas dadas no teste não estiveram vinculadas ao desconhecimento ortográfico das estruturas ouvidas.

A pesquisa a que se vincula este trabalho seguiu todos os procedimentos éticos, tendo sido aprovada pelo Comitê de Ética em Pesquisa do Instituto de Biociências, Letras e Ciências Exatas, da Universidade Estadual Paulista (UNESP), sob o processo de número 64739217.7.0000.5466. Desse modo, seguindo as orientações de ética em pesquisa, para participação no experimento, os participantes da pesquisa assinaram o Termo de Consentimento Livre e Esclarecido aprovado pelo comitê avaliador.

Quanto à forma de análise do teste de percepção, as respostas fornecidas na tarefa completion foram analisadas pelo tipo de complemento proposto para a estrutura relevante. Tendo por base critérios sintático-semânticos, a partir das respostas foi possível avaliar se o participante completou a sentença com elementos previstos pela estrutura sintática. Por exemplo, nos casos em que a estrutura a ser completada foi um verbo, observamos se o participante inseriu um complemento verbal. Na interpretação das respostas, realizamos uma categorização baseada nas classificações identificação e não identificação. As respostas enquadradas na segunda categoria foram sempre de um complemento para a outra estrutura do par, de modo que não foram verificadas respostas que não seguissem essa dinâmica. A seguir, no Quadro 3, apresentamos um exemplo de resposta para os estímulos "compus" e "com pus", destacando se o alvo foi identificado ou não identificado.

Quadro 3. Exemplo de respostas e identificação do alvo investigado

\begin{tabular}{|l|l|l|}
\hline Estímulos diferentes & Ex. de respostas & Identificou o alvo? \\
\hline Hoje cedo compus & uma música & SIM \\
\hline Discutimos contextos & de autores renomados & NÃO \\
\hline Hoje cedo com pus & a minha melhor música & NÃO \\
\hline Discutimos com textos & históricos pertinentes & SIM \\
\hline
\end{tabular}

Fonte: Elaboração própria. 


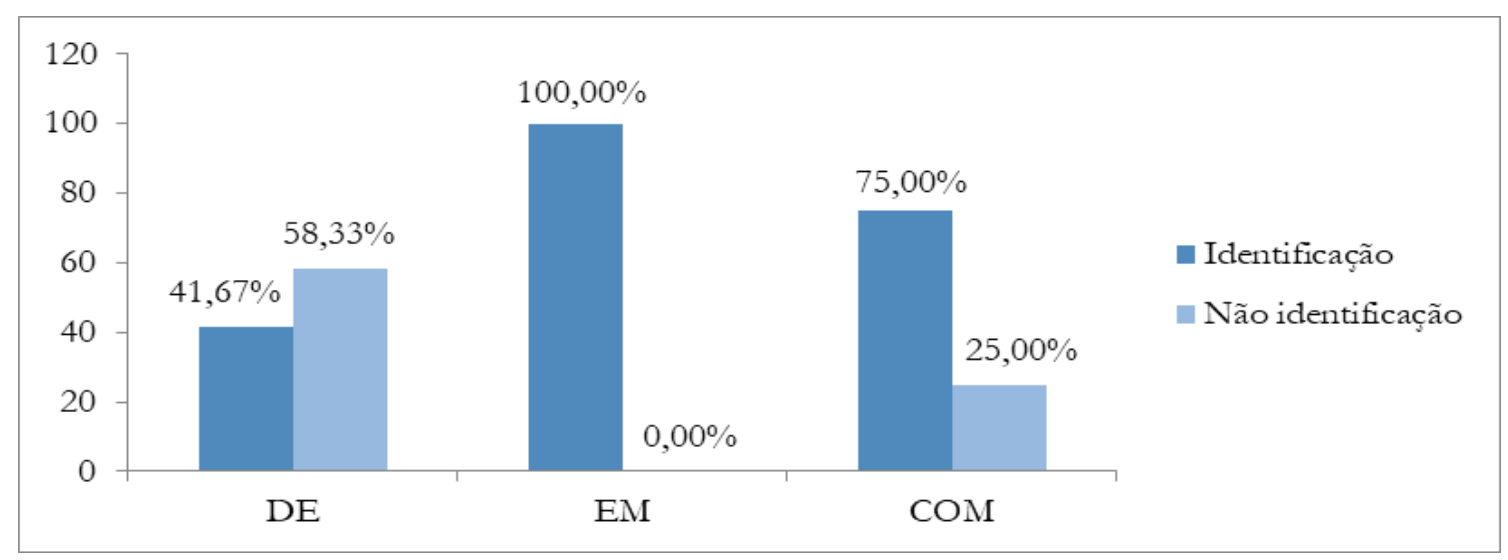

Gráfico 1. Percentual de identificação e de não identificação para o alvo palavra prosódica

Fonte: Elaboração própria.

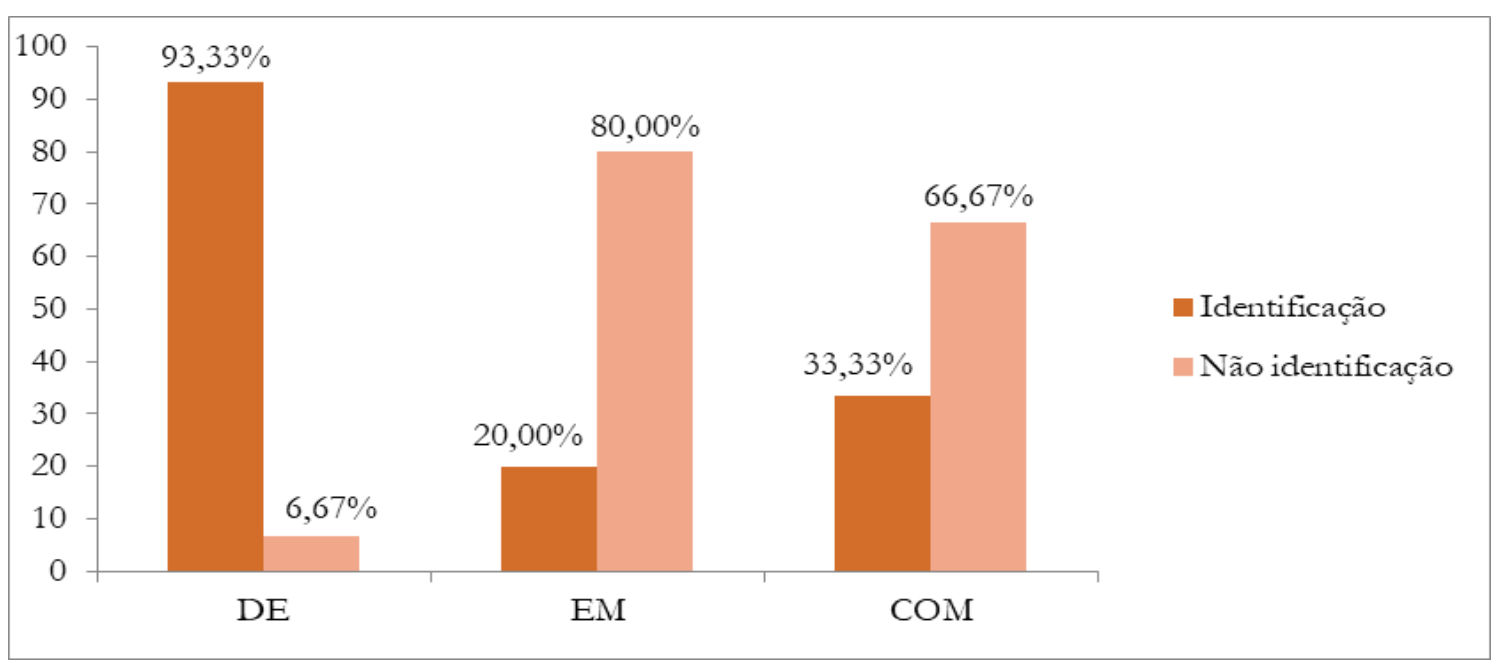

Gráfico 2. Percentual de identificação e de não identificação para o alvo clítico e hospedeiro

Fonte: Elaboração própria.

Em primeiro lugar, fazendo a avaliação entre a identificação e a não identificação da estrutura alvo em função do tipo de sílaba envolvida, é possível destacar que:

(i). Para a sílaba de, quando o alvo é uma palavra prosódica, as respostas são bastante equilibradas, sendo o maior percentual para a categoria de não identificação. No sentido contrário, quando o alvo é a sequência de clítico preposicional e hospedeiro, o maior número de respostas é a de identificação da estrutura alvo. 
(ii). Para a sílaba em, quando o alvo é uma palavra prosódica, todos os estímulos auditivos são corretamente identificados. No entanto, quando o alvo é a sequência de clítico preposicional e hospedeiro, quase a totalidade das respostas revela a não identificação do alvo.

(iii). Para a sílaba com, quando o alvo é uma palavra prosódica, o percentual de identificação é bastante elevado quando comparado ao de não identificação. No caso de o alvo ser uma sequência de clítico e hospedeiro, os percentuais de respostas são bastante equilibrados entre identificação e não identificação da estrutura relevante.

A seguir, a Tabela 1 traz, em valores absoluto e percentual, a distribuição das respostas para cada estímulo envolvendo a sílaba de.

Tabela 1. Identificação/não identificação dos estímulos envolvendo a sílaba de

\begin{tabular}{c|c|c|c|c|c}
\hline $\begin{array}{c}\text { Estímulo: } \\
\text { palavra }\end{array}$ & $\begin{array}{c}\text { Identificação } \\
(\%)\end{array}$ & $\begin{array}{c}\text { Não } \\
\text { identificação } \\
(\%)\end{array}$ & $\begin{array}{c}\text { Estímulo: } \\
\text { cl+hosp. }\end{array}$ & $\begin{array}{c}\text { Identificação } \\
(\%)\end{array}$ & $\begin{array}{c}\text { Não } \\
\text { identificação } \\
(\%)\end{array}$ \\
\hline demais & $0(0,00)$ & $4(57,14)$ & de mais & $5(33,33)$ & $0(0,00)$ \\
\hline depressa & $1(20,00)$ & $3(42,86)$ & de pressa & $5(33,33)$ & $0(0,00)$ \\
\hline decreta & $4(80,00)$ & $0(0,00)$ & de Creta & $5(33,34)$ & $0(100,00)$ \\
\hline Total $(\%)$ & $5(100,00)$ & $7(100,00)$ & Total $(\%)$ & $15(100,00)$ & $0(100,00)$ \\
\hline
\end{tabular}

Fonte: Elaboração própria.

No que diz respeito à configuração das respostas, é possível constatar que a total identificação do estatuto das estruturas alvo ocorreu apenas para o par de estímulos decreta e de Creta. Os estímulos de mais e de pressa foram corretamente percebidos, enquanto seus pares correspondentes tiveram o maior percentual de respostas na classe de não identificação. Desses resultados, destacamos que a percepção integral dos estímulos decreta e de Creta não ocorreu de maneira aleatória, mas fundamentada em uma informação fonológica. Trata-se da aplicação do processo de palatalização da consoante /d/ e alçamento da vogal média /e/ que sempre ocorreu para o clítico, resultando em [dfi] Creta, mas nunca na forma verbal d[e]creta. Diferentemente, é observado que, na variedade do PB falada pelos informantes da pesquisa, esse processo de neutralização não ocorre categoricamente, diferenciando clítico e sílaba pretônica, quando estão em jogo as sequências demais e de mais e depressa e de pressa. De certa forma, entendemos que essa variação na aplicação de processo fonológico se refletiu nas respostas apresentadas para esses estímulos. 
Abaixo, a Tabela 2 expõe os resultados das respostas para os estímulos envolvendo a sílaba em.

Tabela 2. Identificação/não identificação dos estímulos envolvendo a sílaba em

\begin{tabular}{c|c|c|c|c|c}
\hline $\begin{array}{c}\text { Estímulo: } \\
\text { palavra }\end{array}$ & $\begin{array}{c}\text { Identificação } \\
(\%)\end{array}$ & $\begin{array}{c}\text { Não } \\
\text { identificação } \\
(\%)\end{array}$ & $\begin{array}{c}\text { Estímulo: } \\
\text { cl+hosp. }\end{array}$ & $\begin{array}{c}\text { Identificação } \\
(\%)\end{array}$ & $\begin{array}{c}\text { Não } \\
\text { identificação } \\
(\%)\end{array}$ \\
\hline encaixa & $4(33,33)$ & $0(0,00)$ & em caixa & $0(0,00)$ & $5(41,66)$ \\
\hline enquanto & $4(33,33)$ & $0(0,00)$ & em quanto & $3(100,00)$ & $2(16,68)$ \\
\hline enfrente & $4(33,33)$ & $0(0,00)$ & em frente & $0(0,00)$ & $5(41,66)$ \\
\hline Total $(\%)$ & $12(100,00)$ & $0(0,00)$ & Total $(\%)$ & $3(100,00)$ & $12(100,00)$ \\
\hline
\end{tabular}

Fonte: Elaboração própria.

Conforme havia sido apontado com base nos dados do Gráfico 1, todos os estímulos auditivos, cujo alvo era uma palavra prosódica, são corretamente identificados. No que diz respeito às respostas para os estímulos envolvendo estruturas de clítico e hospedeiro, foi verificado que, no geral, dois estímulos não são identificados corretamente (em caixa e em frente) e o maior percentual de respostas para o outro estímulo segue a mesma tendência (em quanto). No caso dos estímulos envolvendo a sílaba em, entendemos que tanto o total de identificação dos estímulos em um grupo alvo quanto a quase unânime não identificação para o outro grupo indica que, quando se tem disponível o mesmo tipo de informação fonética e sintática, não é possível ancoragem para se distinguir o objeto percebido. Nesse sentido, a identificação dos estímulos não é entendida em função das informações presentes unicamente no sinal acústico.

Por fim, na Tabela 3, apresentamos a distribuição do número de respostas para os estímulos envolvendo a sílaba com.

Tabela 3. Identificação/não identificação dos estímulos envolvendo a sílaba com

\begin{tabular}{c|c|c|c|c|c}
\hline $\begin{array}{c}\text { Estímulo: } \\
\text { palavra }\end{array}$ & $\begin{array}{c}\text { Identificação } \\
(\%)\end{array}$ & $\begin{array}{c}\text { Não } \\
\text { identificação } \\
(\%)\end{array}$ & $\begin{array}{c}\text { Estímulo: } \\
\text { cl+hosp. }\end{array}$ & $\begin{array}{c}\text { Identificação } \\
(\%)\end{array}$ & $\begin{array}{c}\text { Não } \\
\text { identificação } \\
(\%)\end{array}$ \\
\hline congestão & $4(44,44)$ & $0(0,00)$ & com gestão & $0(0,00)$ & $5(50,00)$ \\
\hline compus & $4(44,44)$ & $0(0,00)$ & com pus & $0(0,00)$ & $5(50,00)$ \\
\hline contexto & $1(11,12)$ & $3(100,00)$ & com texto & $5(100,00)$ & $0(0,00)$ \\
\hline Total $(\%)$ & $9(100,00)$ & $3(100,00)$ & Total $(\%)$ & $5(100,00)$ & $10(100,00)$ \\
\hline
\end{tabular}

Fonte: Elaboração própria 
Considerando os pares de estímulos congestão e com gestão e compus e com pus, é possível perceber a correta identificação para o alvo palavra prosódica e a não identificação quando o alvo se tratava de uma sequência de clítico e hospedeiro. Já para o par contexto e com texto, nota-se que as respostas vão no sentido contrário, pois todas as identificações ocorreram para o alvo clítico e hospedeiro e a não identificação quase integral se deu para quando o alvo foi uma palavra prosódica. Nesse sentido, as informações da Tabela 3 seguem as mesmas direções de respostas observadas para os estímulos envolvendo a sílaba em, no sentido de que apenas informações presentes no sinal acústico não ancoram a percepção das diferentes estruturas faladas.

Tendo em vista os resultados apresentados, é possível destacar que simplesmente o estímulo auditivo (aspecto físico do sinal acústico) não foi suficiente para a percepção da estrutura a ser completada. Para embasar essa conclusão, tivemos como evidência a análise das estruturas alvo, a partir da qual se notou uma distinção clara entre a percepção das sequências encabeçadas pela sílaba de daquelas que foram iniciadas pelas sílabas em e com. Quando aliado ao sinal acústico esteve presente uma informação fonológica sobre aplicação de processo de alçamento vocálico, como foi o caso do par decreta e de Creta, por exemplo, foi categórica a identificação de duas unidades linguísticas distintas. Por sua vez, quando as estruturas alvo envolveram as sílabas em e com, ainda que em muitos casos a identificação tenha sido correta, esse acerto pareceu ocorrer aleatoriamente, já que de um modo geral foi sempre privilegiada apenas uma das estruturas homófonas (dentre as possibilidades do par). Por exemplo, no par congestão e com gestão, os participantes que responderam ao alvo palavra sempre identificaram essa estrutura, enquanto os sujeitos que ouviram o estímulo composto pela sequência de clítico e hospedeiro não identificaram o estatuto da sequência ouvida. Nesse caso, temos como hipótese que a correta identificação teria como pista uma interpretação fundamentada no campo semântico da forma congestão da sequência anterior à estrutura relevante, a saber, "o Bruno sofreu", pois, nesse caso, estão vinculadas acepções que podem indicar problemas relacionados à saúde. Assim, esses resultados nos permitem defender que: 1) estímulo auditivo e informação sintática parcial contribuem para a não percepção de uma estrutura aparentemente idêntica; 2) o sinal acústico não é ancoragem suficiente e é necessário estar associado à informação distintiva (estabelecendo relação entre aspectos fonéticos e fonológicos).

Assim, considerando possibilidades de conceituação de percepção de fala, os resultados vão de encontro a visões que relacionam esse processo como algo puramente auditivo, pois se assim o fosse todas as estruturas testadas teriam sido identificadas independentemente da ausência de outras informações linguísticas, bastando, portanto, a presença do sinal acústico (plano físico). O design da tarefa perceptiva realizada, nesse sentido, contribuiu para a visão de que a percepção é multissensorial (SCHWARTZ et al., 2012), uma vez que junto ao plano físico do sinal acústico atuam outras informações linguísticas, como, por exemplo, a representação abstrata dos sons da língua e como ela é importante para distinguir unidades diferentes. 
Assim, entende-se que a categorização de uma unidade, enquanto duas estruturas linguísticas distintas, é dependente de mais de uma informação linguística, já que apenas uma informação (como a sonora, em nosso teste) não é suficiente para identificar estruturas que são confirmadamente diferentes tanto do ponto de vista prosódico quanto do ponto de vista sintático-semântico.

\section{Considerações finais}

Neste trabalho, foram apresentados dados de percepção de fala que envolviam a identificação de palavras prosódicas e de estruturas de clítico e hospedeiro correspondentes, respectivamente, à mesma cadeia segmental. Com o teste de percepção desenvolvido, foi possível observar que, ao contrário do que se atesta para o PB em relação à palavra prosódica e às sequências de clítico e hospedeiro se constituírem como unidades diferentes, os dados de percepção não são categóricos quanto a tal distinção.

Nesse sentido, os dados de percepção não corroboram totalmente a premissa de que palavra prosódica e sequências de clítico e hospedeiro são estruturas prosódicas distintas em PB. Na medida em que, com base em dados de fala, é bastante consensual a diferença entre ambas as estruturas, o presente trabalho lança como desenvolvimento futuro a problematização do estatuto de dados de percepção quando se está em jogo a constituição da estrutura prosódica.

\section{REFERÊNCIAS}

ANDRÉ, C. et al. PERCEVAL: PERCeption EVALuation Auditive \&Visuelle (Versão 4.0.0.0) [Programa de Computador]. Aix-en-Provence, 2017.

BISOL, L. O clítico e o seu hospedeiro. Letras de Hoje, Porto Alegre, v. 40, n. 3, p. 163-184, 2005.

BISOL, L. O clítico e seu status prosódico. Revista de Estudos da Linguagem, Belo Horizonte, v. 9, n. 1, p. 5-20, 2000.

CÂMARA JR., J. M. Princípios de linguística geral: como introdução aos estudos superiores da língua portuguesa. 4. ed. Rio de Janeiro: Acadêmica, 1964.

CÂMARA JR., J. M. Estrutura da língua portuguesa. Petrópolis: Vozes, 1970.

FROTA, S. Prosody and focos in Euroupean Portuguese: phonological phrasing and intonation. New York: Garland Publishing, 2000. 
HAYES, B. The prosodic hierarchy in meter. In: KIPARSKY, P.; YOUMANS, G. (ed.). Rhythm and Meter. Orlando: Academic Press, 1989. p. 201-260.

MILLOTE, S.; WALES, R.; CHRISTOPHE, A. Phrasal prosody desambiguates syntax. Language and cognitive processes, v. 22, p. 898-909, 2007.

NESPOR, M.; VOGEL, I. Prosodic phonology. Dordrechet: Foris Publications, 1986.

NESPOR, M.; VOGEL, I. Prosodic Phonology: with a new foreword. Berlim/New York: Mouton de Gruyter, 2007.

SCHWARTZ, J. et al. The Perception for Action Control Theory (PACT): a perceptuo-motor theory of speech perception. Journal of Neurolinguistics, Élsevier, v. 5, n. 25, p. 336-354, 2012.

SELKIRK, E. Phonology and Syntax: the relation between sound and structure. The Massachusetts Institute Technology, 1984.

SELKIRK, E. The prosodic structure of function words. In: MORGAN, J.; DEMUTH, K. (ed.). Signal to syntax: bootstrapping from speech to grammar in early acquisition, Mawhaw $\mathrm{NJ}$ : Lawrence Erlbaum, 1996. p. 187-213.

SEVERINO, C. Fronteiras prosódicas e desambiguação no Português Europeu. 2011. Dissertação (Mestrado em Letras) - Universidade de Lisboa, Lisboa, 2011.

SILVA, L. M.; TENANI, L. Hipersegmentações de palavra no ensino fundamental. São Paulo: Cultura Acadêmica, 2014.

SILVA, L. M. Grafias não convencionais de preposições e sílabas pretônicas: pistas de prosodização de clíticos preposicionais. 2018. Tese (Doutorado em Estudos Linguísticos) - Instituto de Biociências, Letras e Ciências Exatas, Universidade Estadual Paulista, São José do Rio Preto, 2018.

SIMIONI, T. O clítico e seu lugar na estrutura prosódica em português brasileiro. ALFA, São Paulo, v. 52, n. 2, p. 431-446, 2008.

TENANI, L. Entre o grupo clítico e a palavra fonológica: os erros de segmentação nãoconvencional de palavras. Comunicação apresentada no VI Congresso Internacional da ABRALIN, 2009. 
TENANI, L. Prosódia e escrita: uma análise a partir de (hiper)segmentações de palavra. 2016. Tese (Livre-Docência em Fonologia) - Instituto de Biociências, Letras e Ciências Exatas, Universidade Estadual Paulista, São José do Rio Preto, 2016.

TENANI, L.; FIEL, R. P. O papel de estruturas prosódicas e morfossintáticas em hipossegmentações do Ensino Fundamental-II. Revista do Gel, São Paulo, v. 13, n. 3, p. 107-129, 2016.

VELOSO, J. Unidades acentuais proproparoxítonas e grupos clíticos em português. 2012. Disponível em: http://bit.ly/2Y007A2. Acesso em: 10 jul. 2018.

VIGÁRIO, M. The prosodic word in European Portuguese. Berlim/New York: Mouton de Gruyter, 2003.

VIGÁRIO, M. Prosodic structure between the prosodic word and the phonological phrase: recursive nodes or an independent domain? The Linguistic Review, n. 27, p. 485-530, 2010.

VOGEL, I. The status of the Clitic Group. In: GRIJZENHOUT, J.; KABAK, B. (ed.). Phonological Domains: universals and deviations. Mouton de Gruyter, 2009. p. 15-46. 